\title{
Self-expanding plastic stents for the treatment of post-operative esophago-jejuno anastomosis leak. A case series study
}

\author{
A. Fernández, J. J. Vila ${ }^{1}$, S. Vázquez, C. González-Portela, M. de la Iglesia, M. Lozano² and E. Toscano² \\ Gastroenterology Department. POVISA Hospital. Vigo. Spain. ${ }^{\prime}$ Gastroenterology Department. Hospital de Navarra. \\ Pamplona. Spain. ${ }^{2}$ Surgery Department. POVISA Hospital. Vigo. Spain
}

\begin{abstract}
Objetive: Self-expandable plastic stents (SEPS) are increasingly being used for treatment of postoperative esophageal leak. This complication occurs in $4-27 \%$ of patients after radical gastrectomy, and has a high mortality rate up to $60 \%$.

The aim of this study is to evaluate the efficacy of SEPS $\left(\right.$ Polyflex $\left.^{\circledR}\right)$ for treatment of post-operative eshopago-jejuno anastomosis leak after radical gastrectomy for gastric cancer.

Material and methods: During one year period patients who underwent a radical gastrectomy in our hospital for gastric cancer and developed a postoperative anastomotic leak were prospectively included in the study after signing a consent form, and treated with SEPS placement under endoscopic and fluoroscopic control for leak occlusion.

Results: Four patients were included ( 3 men/ 1 woman). The mean interval between operation and SEPS placement was 16 days (range: 4-34). SEPS deployment was easily performed in all patients with complete occlusion of esophageal lumen in three patients. In the fourth patient we needed to deploy a second coaxial stent to achieve a complete occlusion of the fistula. SEPS migration did not happen in our series. One patient had already developed a mediastinitis by the time we placed the SEPS and he died 3 days later. Extraction of the SEPS was easily performed 4-8 weeks after deployment.

Conclusion: We achieved a complete healing of the anastomotic fistula after radical gastrectomy in 3 out of 4 patients, without major complications related to SEPS. Placement of SEPS is an appealing minimally invasive alternative to surgical repair for patients with postoperative anastomotic leak.
\end{abstract}

Key words: Endoscopy. Esophago-jejunal anastomotic leak. Gastric cancer. Stents. Treatment.

Recibido: 04-03-10.

Aceptado: 30-04-10.

Correspondencia: Alberto Fernández Villaverde. Servicio de Aparato Digestivo. Hospital POVISA. C/ Salamanca, 5. 36211 Vigo. Pontevedra, Spain.e-mail: afvillaverde@gmail.com
Fernández A, Vila JJ, Vázquez S, González-Portela $C$, de la Iglesia M, Lozano M, Toscazo E. Self-expanding plastic stents for the treatment of post-operative esophago-jejuno anastomosis leak. A case series study. Rev Esp Enferm Dig 2010; 102: 704-710.

\section{INTRODUCTION}

Surgery is the best therapeutic option for patients with localized gastric cancer. Total or partial gastrectomy is related with possible major complications, including anastomotic leaks. This complication occurs in $4-27 \%$ of patients after radical gastrectomy, and has a high mortality rate up to $60 \%$ (1-3). There are different approaches in the management of esophageal leaks, including surgery or, in the case of minor fistulas, conservative management (4). Surgical repair of esophageal leaks involve a risky intervention with important consumption of hospital resources and prolonged in-hospital stay. Endoscopic techniques such as clipping (5) or fibrin glue application (6-8) have been proposed as an alternative, but with poor results, particularly in the cases of extensive dehiscences. Self-expandable plastic stents (SEPS) are increasingly being used for treatment of postoperative esophageal leak with good efficiency and safety (9-11).

The aim of this study was to evaluate the efficacy of SEPS (Polyflex ${ }^{\circledast}$. Boston Scientific Corp. Nattick. Massachuset. United States.) in the management of post-operative esophago-jejuno anastomosis leak after radical gastrectomy for gastric cancer.

\section{MATERIAL AND METHODS}

\section{Patients}

During a 12 months period (December 2007-November 2008) patients who underwent a radical gastrectomy 
in our hospital for gastric cancer and developed a postoperative anastomotic leak were prospectively eligible to be include in our study. Those patients with an anastomotic leak who signed an informed consent were endoscopically treated.

\section{Diagnosis and treatment of anastomotic leaks}

Diagnosis of esophago-jejuno anastomotic leak was made using water-soluble contrast (swallowing or using a naso-jejunal feeding tube), at day 5-7 after surgery by protocol, or earlier in cases with a clinical suspicion of anastomotic leak. All included patients were treated by means of SEPS (Polyflex ${ }^{\circledR}$. Boston Scientific Corp. Nattick. Mass), placement was performed by an endoscopist under fluoroscopic and endoscopic control, with the patient in the left lateral decubitus position. Patients were under general anesthesia. During the procedure, an initial gastroscopy was performed in order to define the characteristics of the fistula and mark its location with an external radiopaque marker. Afterwards, a Savary guide wire was placed through the scope deeply in the efferent loop of the jejunal anastomosis. The gastroscope was then pulled out and the SEPS was introduced over the guide wire and deploy under fluoroscopic control, with the help of the external marker for correct placement. The Polyflex stent must be loaded on the introductor immediately before insertion because the plastic, unlike metal, does not stay folded long time without being damaged. The effectiveness of leak occlusion and the correct placement of the stent were evaluated by water-soluble contrast swallow performed 24 hours after stent placement, and, patients remained in decubitus position for 48 hours. Feeding was immediately started with liquids after the verification of the leak occlusion, and soft diet plus enteral supplements were added 24 hours later. The extraction of the stent was performed endoscopically 4-8 weeks after deployment, using rat-tooth forceps, grasping at the proximal end and pulling out, with fluoroscopic assistance and also under general anesthesia. Finally, complete closure of the leak was verified by radiological contrast study performed after stent extraction.

\section{RESULTS}

During this period (December 2007-November 2008) 38 patients (23 men, 15 women) diagnosed of gastric cancer were operated, with a median age of 74 years (range: 56-89). Radical gastrectomy was performed in 13 patients and distal gastrectomy in 15 patients, all of them associated to a D2 lymphadenectomy. Clear resection margins were obtained in all patients. In the remaining 10 patients palliative treatment was attempted (gastro-jejunostomy or surgical gastrostomy or jejunostomy), due to the irresectability of the tumor.
During this period, 4 patients ( 3 men/ 1 woman) with a median age of 79 years (range: 65-89) were diagnosed of esophago-jejuno anastomotic leak after radical gastrectomy. The mean interval between operation and SEPS placement was 16 days (range: 4-34). SEPS migration did not happen in our series. The evolution of the patient after placement of the stents is commented separately.

\section{Patient 1}

An 88-year-old woman with a T1N0M0 gastric cancer, treated by laparoscopic radical gastrectomy, developed a postoperative leak. A 25/21 mm diameter and $9 \mathrm{~cm}$ long SEPS was placed without complications 27 days after surgery. Perianastomotic drainage tubes were placed during surgery, and extracted with cessation of drainage after leak occlusion with stent placement (Fig. 1). In spite of that, this patient developed a residual perijejunal collection which was percutaneously drained. She resumed oral intake three days after stent placement and 9 days later she was discharged. Retrieval of the stent was easily per-

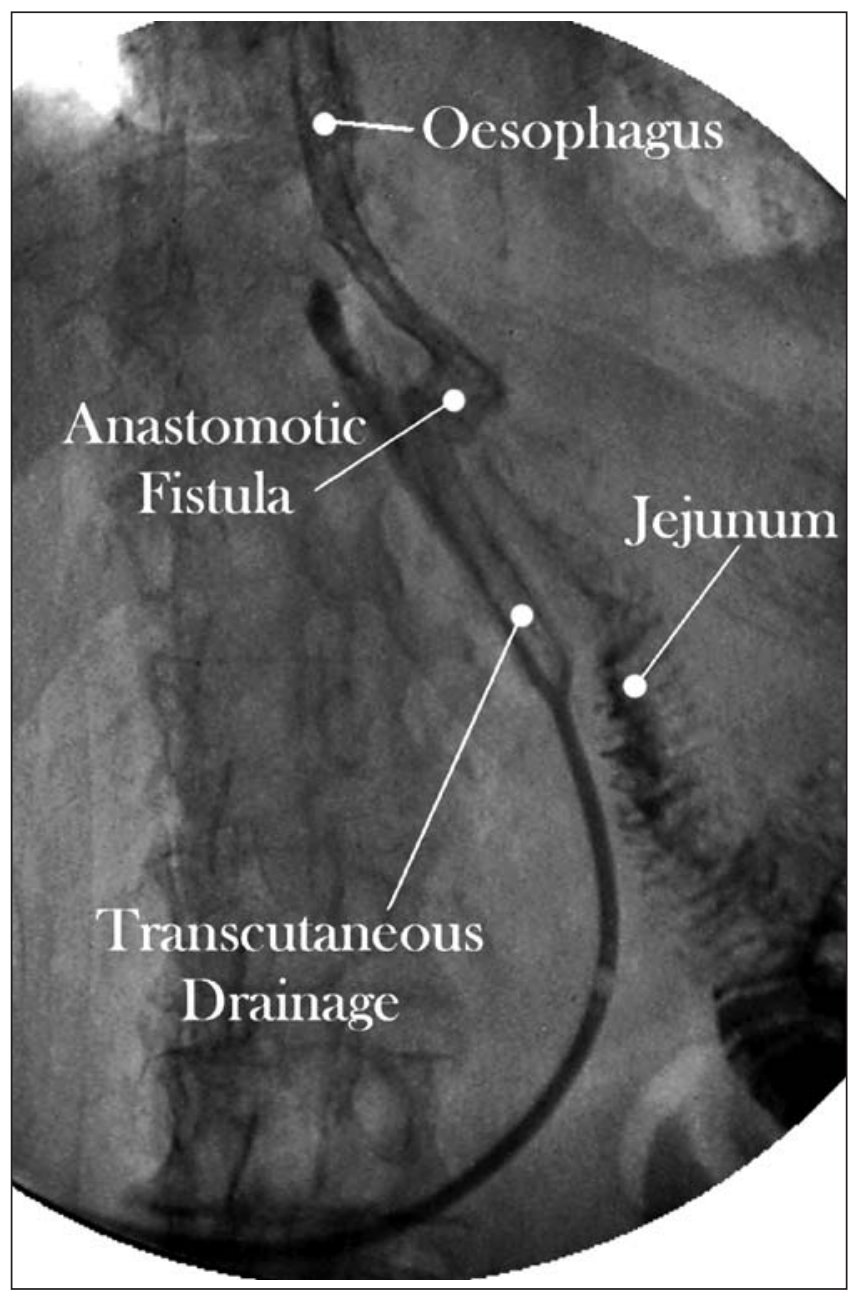

Fig. 1. Patient 1: radiological image of the anastomotic fistula. 
formed 4 weeks later, and healing of the leakage was radiologically proved. Her only complain was a mild thoracic pain, which started after SEPS placement and persisted until extraction.

\section{Patient 2}

A 65-year-old man diagnosed of a T2bN2M0 gastric cancer who underwent a laparoscopic radical gastrectomy with a postoperative leak. A 25/21 mm diameter and 9 $\mathrm{cm}$ long SEPS was easily placed 4 days after surgery. In the radiological control the fistula persisted, because of incomplete occlusion of the esophageal lumen by the proximal end of the SEPS. In this case, the incomplete occlusion was probably due to the stent stiffness. Thus, placement of the stent deeply in the jejunal efferent loop led to a tilted position of the stent with creation of an angle between the proximal end of the stent and the esophageal wall, which caused an incomplete occlusion of the esophageal lumen. For this reason the same stent was placed $3 \mathrm{~cm}$ higher and, in the same session, we placed a second coaxial SEPS orientated to the efferent intestinal loop (Fig. 2). During this replacement proce-

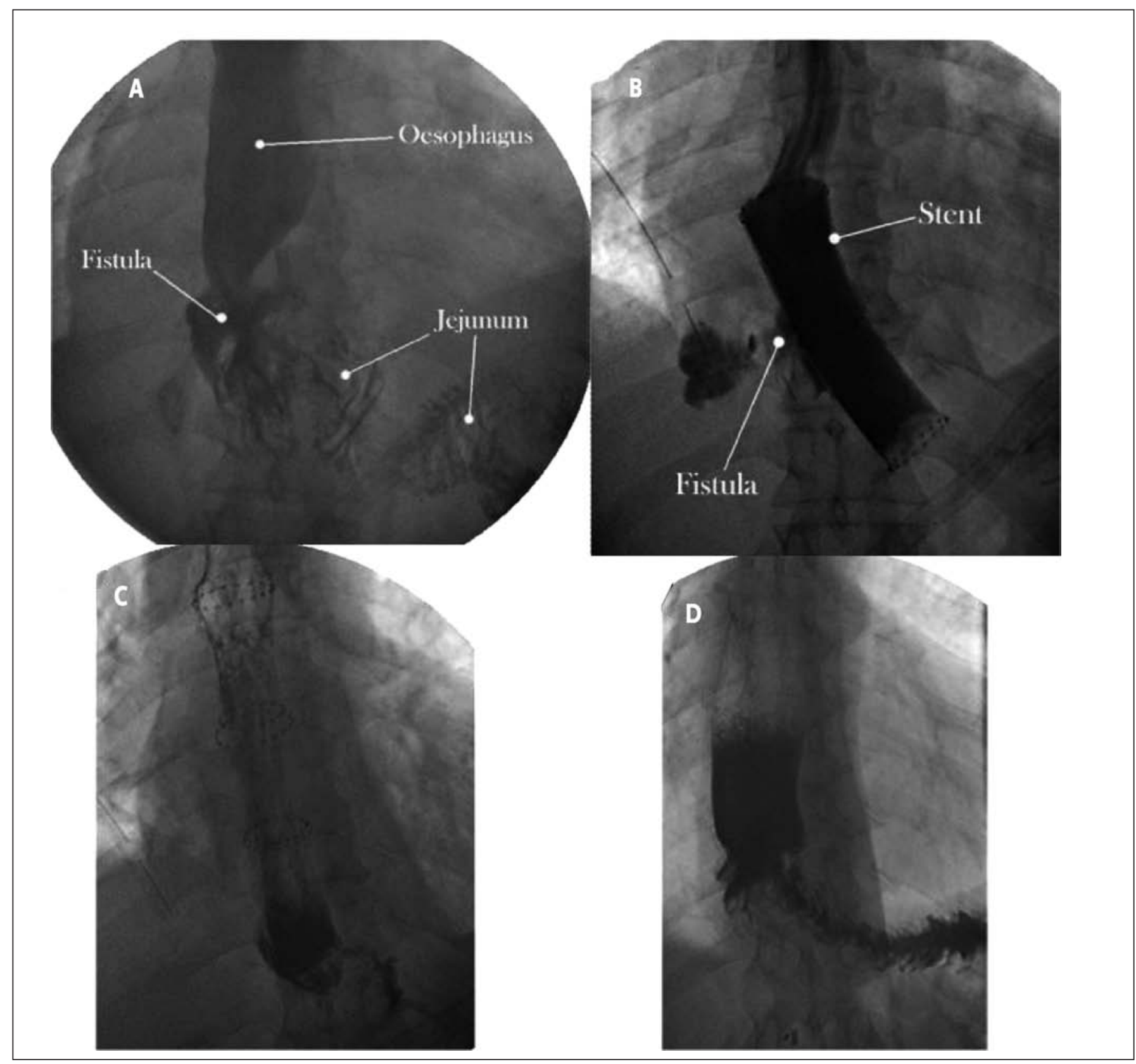

Fig. 2. Patient 2. A: Radiological image of the anastomotic fistula. B: Persistence of fistula after placement of the first stent. C: Effectiveness of leak occlusion after replacement of the fist stent and placement of a second stent. D: Complete closure of the leak after stent extraction. 
dure, the first stent was easily extracted, assembled again in the introductor and repositioned without difficulty. Probably related to an incomplete pleural drainage and closure of the fistula, this patient developed an empyema which was uneventfully drained with a thoracic tube. The patient started oral intake three days after the procedure. Both SEPS were left in place for 8 weeks, and afterwards were easily extracted. The radiological contrast study confirmed the healing of the fistula.

\section{Patient 3}

An 89-year-old man with a T2N0M0 gastric cancer, treated with laparoscopic radical gastrectomy developed a postoperative leak. Ten days after surgery we easily placed a 21/25 $\mathrm{mm}$ diameter and $12 \mathrm{~cm}$ long SEPS (Fig. $3)$. Unfortunately, by the time the stent was placed, the patient has already developed a mediastinitis which got worse despite SEPS placement, antibiotic therapy and an apparently good drainage by means of mediastinum drainage tubes and thoracic drainage tubes placed during surgery. He finally died 3 days after stent placement.

\section{Patient 4}

A 75-year-old man with a postoperative esophago-jejuno anastomosis leak after laparoscopic radical gastrec- tomy due to a pT3N2M0 gastric cancer. A 25/21 mm diameter and $9 \mathrm{~cm}$ long SEPS was placed without complications. This patient presented mild retroesternal chest pain. A big postoperative fluid collection around $10 \mathrm{~cm}$ in diameter was diagnosed and treatment with percutaneous drainage was required. The extraction of the stent was performed 4 weeks later, but the radiological study showed the persistence of a minor fistula. Placement of a second stent was offered but rejected for the patient because of the clinical intolerance reported. Due to the small size of the fistula, we decided to place a nasojejunal feeding tube, distal to the anastomosis. Four weeks later, closure of the leak was confirmed by means of a contrast swallow study (Fig. 4).

In the cases of patient 1, 2 and 4 there was a mild-tomoderate overgrowth of granulation tissue in the proximal edge of the stent. In order to avoid complications during the extraction procedure, previously, we gently pushed down the SEPS to liberate its proximal end, and afterwards we grasped the stent by its proximal end with the rat-tooth forceps and pulled out without difficulty.

\section{DISCUSSION}

This study describes our initial experience with SEPS for treatment of post-operative esophaho-jejuno anastomosis leak. Endoscopic treatment of these leakages with self expandable metallic stents (SEMS) has been attempt-

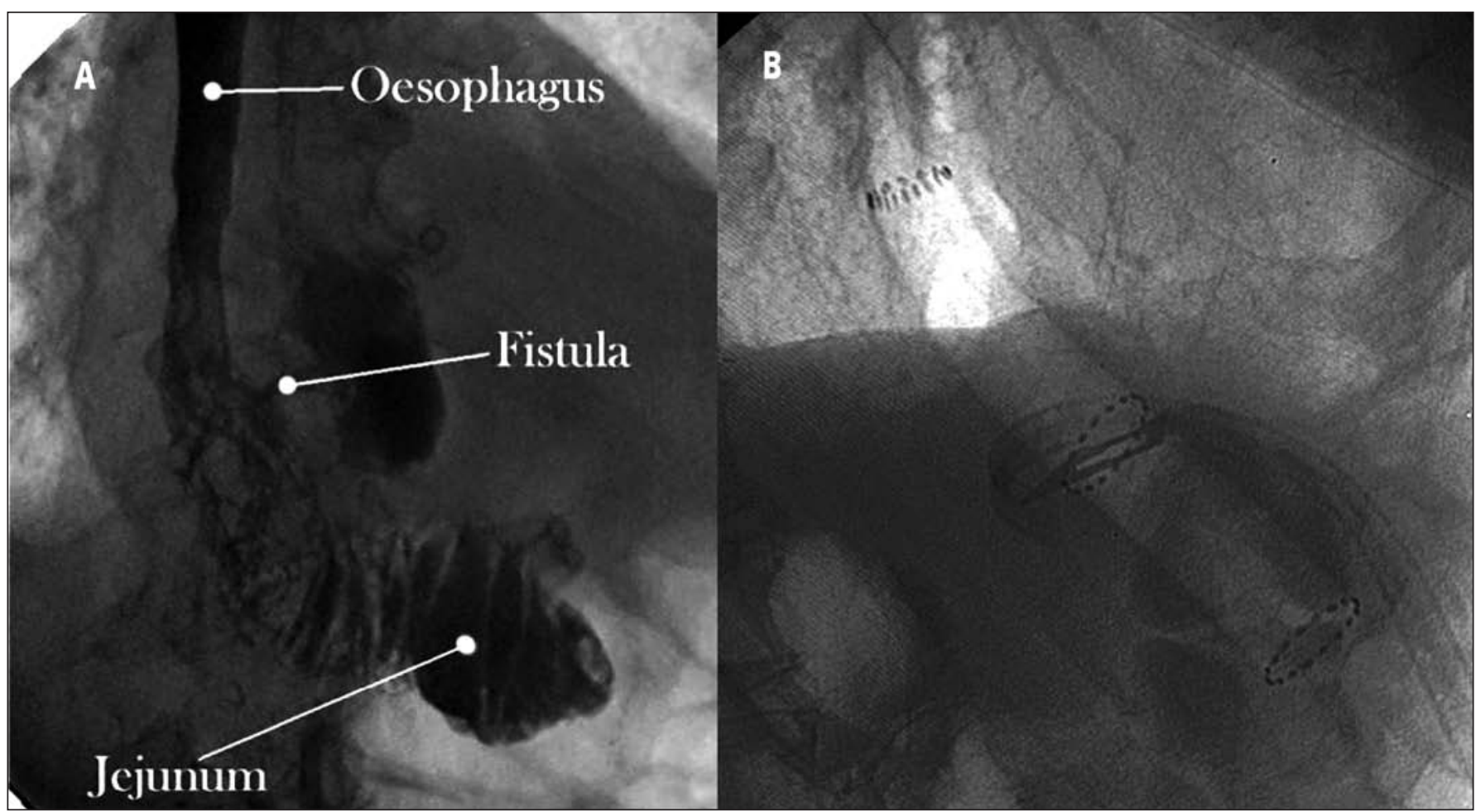

Fig. 3. Patient 3. A: Radiological image of the anastomotic fistula. B: Radiological image of the stent with radiopaque marker and thoracic drainage tube with apparently good drainage. 


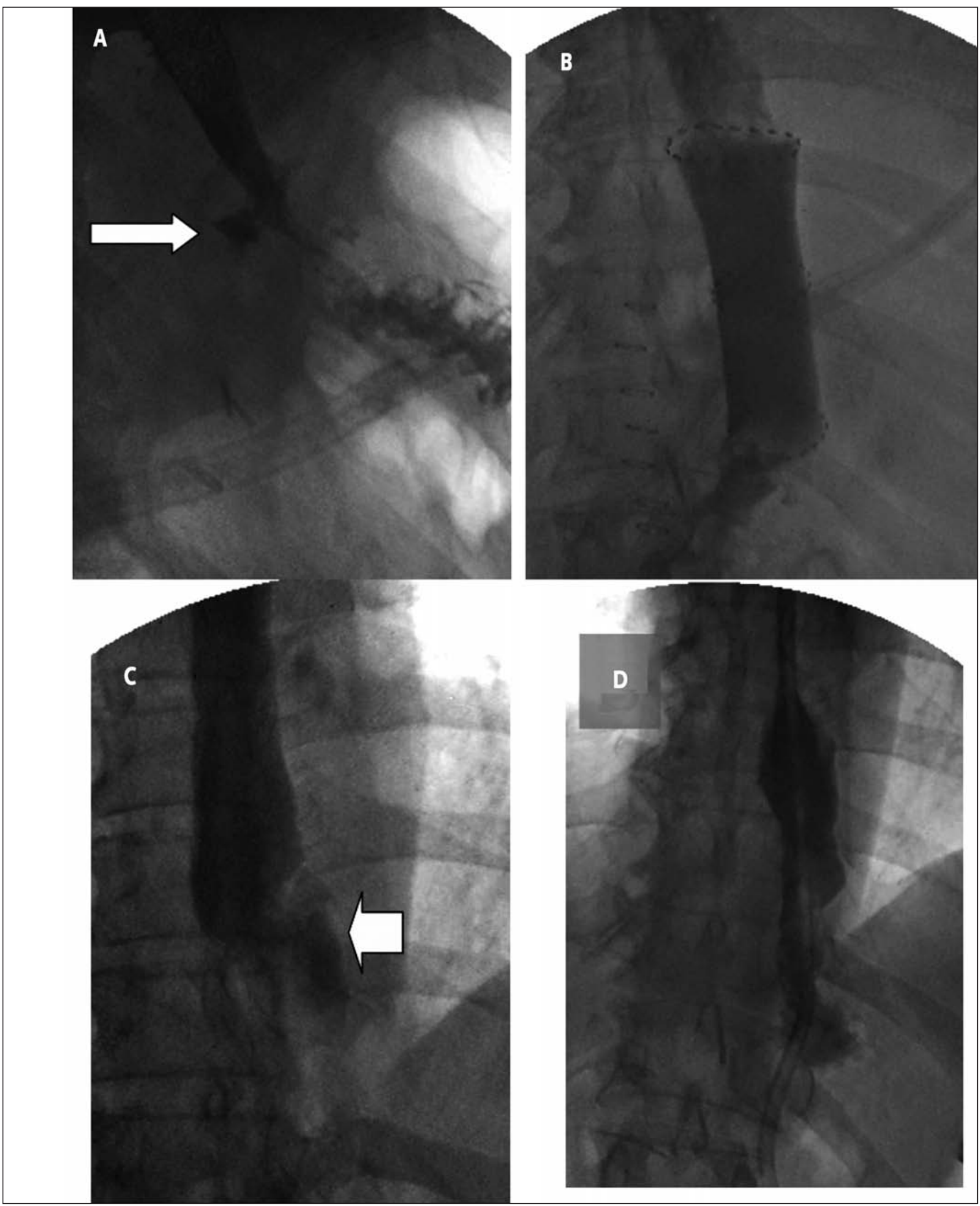

Fig. 4. Patient 4. A: Radiological image of the anastomotic fistula (long arrow). B: Apparently good closure of the fistula with the stent. C: Persistence of fistula after the stent extraction. D: Complete closure of the fistula four weeks after nasojejunal tube placement. 
ed, with fairly goods results but with a high rate of complications such as perforation, hemorrhage, migration or obstruction (12-17). The main drawback to use uncovered SEMS for treatment of esophageal benign disease is that metallic stents mostly become strongly embedded into the esophageal wall and retrieval might be extremely difficult or impossible $(9,18)$. SEPS implantation within a metallic stent has proved to be a valid option to get rid of this situation $(9,19)$. A major drawback to use SEMS in this setting is development of hyperplastic inflammatory tissue through the open mesh of the stent (20). This might result in late onset dysphagia. On the other hand, Polyflex ${ }^{\circledR}$ is a totally covered woven plastic stent made of polyester netting embedded in silicone with two radiopaque marker rings located at both ends and another in the middle of the stent. The Polyflex sent has been approved for use in the management of beningn and malignant esophageal stricture (21). SEPS have been successfully used to treat benign esophageal disorders, including postoperative fistulas (9-11,18,22-33). SEPS are easily placed under fluoroscopic or endoscopic control and allow an early removal since they do not become embedded into the gut wall. According to the published data the use of SEPS reduce the rate and duration of long term ventilation and it is associated with an earlier oral intake and a shorter invasive care course and in-hospital stay compared with the conventional surgical treatment (11). Stent migration range from 22 to $40 \%$, and the use of longer stents could reduce the rate of dislocation $(11,31)$.

In the four cases we decided to use SEPS to seal the fistula and allow an early stent removal. It is not clearly defined how long the stent should be left in place for treatment of postoperative fistulas. The majority of the fistulas treated with SEPS reported in the literature are closed before the sixth week after stent placement $(9,11)$, thus stent extraction should be attempted earlier. On the other hand, migration is a relatively common complication in this setting, and this was our major concern using SEPS, since none of the patients had anastomotic stenoses which might hold the stent in place. Furthermore, if migration occurred, patients did not have stomach to retain the stent and prevent distal migration with possible complications (32). Evrad et al treated four patients with esophageal anastomotic fistula with SEPS, and migration occurred in three of them, but in only one patient before the fourth week after placement (9). So, taking into account that four weeks seem to be enough to facilitate the closure of the fistula and migration is more common in the long-term treatment, we finally decided to use SEPS to treat our patients and perform an early extraction. We also took other precautionary measures in order to prevent migration. Thus, we used the stent with the greatest diameter available in order to occlude completely the esophageal lumen and anchor the stent in place. This might have an influence on the thoracic pain referred by two of our patients. We also waited 48 hours with the patient in decubitus position to favor the com- plete expansion of the stent. Actually we do not know whether any of these maneuvers played any role to prevent migration. In our series, deployment of of the SEPS was easily performed in all cases, and we did not need to move any stent immediately after deployment. In three of the four cases, a complete immediate leak occlusion was obtained without procedure-related morbidity. In our second patient we had to deploy a second coaxial stent to completely occlude the esophageal lumen. From our point of view, this was a consequence of the stiffness of the stent combined with the surgical reconstruction since the esophagus and the jejunal loop were not the same longitudinal axis and an angulation was formed. Due to these circumstances, in this patient we delayed the extraction of the stent until the week 8 , in order to make sure the complete closure of the fistula.

We had not complications related with retrieval of the stent. In the fourth patient complete closure of the fistula was not achieved, probably related to a prompt removal due to the chest pain. In this patient we should have waited at least 2 more weeks, but the patient rejected placement of another stent due to chest pain.

Percutaneous interventional drainage was required in three of the four patients after stent placement despite an apparently good mediastinal and pleural drainage. An effective external drainage of the perianastomotic mediastinum is mandatory because occlusion of the fistula with the stent prevents internal drainage to the digestive tract and favors formation of fluid collections. Thus before deployment of the stent, and appropriate external drainage by means of chest or perianastomotic tube must be guaranteed and placement of additional catheters should be possible. Our third patient already had developed a mediastinitis when the stent was placed, and despite external drainage and antibiotic therapy he had a dreadful evolution and died three days after stent placement. We must emphasize that anastomotic leakage is a severe complication with a high rate of morbidity and mortality, which might be as high as $60 \%$ in surgical series (33).

According to our experience, the use of SEPS in the treatment of postoperative leaks brings forward clear benefits. The rate of immediate leak occlusion is high. We did not find technical difficulties in the placement and retrieval procedure. Moreover, taking into account the previous data, SEPS seems to reduce the in-hospital stay, and allows an earlier oral intake, which is clearly related with a better outcome (11). In our series all the patients who developed an anastomotic leak after radical gastrectomy where included in the study, so, we do not have a control group to compare the results, but the morbidity and mortality of this procedure seems to be clearly low comparing with the surgical alternative, taking into account that we are managing high risk clinical situations and, as we shown in our series, old patients in most of the cases. Nevertheless, there are some open questions, such as the time period that the stent should be left in place, since a prompt extraction could lead to an incomplete 
closure of the leak; and a delayed retrieval is related with migration or presence of overgrowth tissue. Further studies should be performed to improve the outcome of this technique.

In conclusion, the placement of SEPS is an appealing minimally invasive alternative to surgical repair for patients with postoperative leak, it seems to be technically feasible, safe and effective. Plastic stents probably reduce the morbidity and mortality associated with this lifethreatening complication.

\section{REFERENCES}

1. Ikeguchi M, Oka S, Goymo Y, Tsujitani S, Maeta M, Kaibara N. Postoperative morbidity and mortality after gastrectomy for gastric carcinoma. Hepatogastroenterology 2001; 48: 1517-20.

2. Lang H. Piso P, Stukenborg C, Raab R, Jahne J. Management and results of proximal anastomotic leak in a series of 1114 total gastrectomies for gastric carcinoma. Eur J Surg Oncol 2000; 26: 168-71.

3. Nowakowski P, Ziaja K, Ludyga T, Kuczmik W, Biolik G, Cwik P, et al. Self-expandable metallic stents in the treatment of post-esophagogastrostomy/post-esophagoenterostomy fistula. Dis Esophagus 2007; 20: 358-60.

4. Sauvanet A, Baltar J, Le Mee J, Belghiti J. Diagnosis and conservative management of intrathoracic leakage after oesophagectomy. Br J Surg 1988; 85: 1446-9.

5. Rodella L, Laterza E, De Manzoni G, Kind R, Lombardo F, Ricci F, et al. Endoscopic clipping of anastomotic leakages in esophagogastric surgery. Endoscopy 1998; 30: 453-6.

6. Pross M, Manger T, Reinheckel T, Mirow L, Kunz D, Lippert H. Endoscopic treatment of clinically symptomatic leakages of thoracic esophageal anastomoses. Gastrointest Endosc 2000; 51: 73-6.

7. García-Moreno JL, Suárez Grau JM, Gómez Bravo MA, Álamo Martínez JM, Domínguez Usero D, Valera Sánchez L, et al. Closure of gastrocutaneous fistula using endoscopic biological glue injection. Rev Esp Enferm Dig 2007; 99: 676-7.

8. Rábago LR, Castro JL, Joya D, Herrera N, Gea F, Mora P, et al. Esophageal perforation and postoperative fistulae of the upper digestive tract treated endoscopically with the application of Tissucol. Gastroenterol Hepatol 2000; 23: 82-6.

9. Evrard S, Le Moine O, Lazaraki G, Dormann A, El Nakadi I, Devière J. Self-expanding plastic stents for benign esophageal lesions. Gastrointest Endosc. 2004; 60: 894-900.

10. Gelbmann CM, Ratiu NL, Rath HC, Rogler G, Lock G, Schölmerich $\mathrm{J}$, et al. Use of self-expandable plastic stents for the treatment of esophageal perforations and symptomatic anastomotic leaks. Endoscopy. 2004; 36: 695-9.

11. Hünerbein M, Stroszczynski C, Moesta KT, Schlag PM. Treatment of thoracic anastomotic leaks after esophagectomy with self-expanding plastic stents. Ann Surg 2004; 240: 801-7.

12. Kozarek RA, Raltz S, Brugge WR, Schapiro RH, Waxman I, Boyce $\mathrm{HW}$, et al. Prospective multicenter trial of esophageal Z-stent placement for malignant dysphagia and tracheoesophageal fistula. Gastrointest Endosc. 1996; 44: 562-7.

13. Raijman I, Siddique I, Ajani J, Lynch P. Palliation of malignant dysphagia and fistulae with coated expandable metal stents: experience with 101 patients,. Gastrointest Endosc 1998; 48: 172-9.

14. Roy-Choudhury SH, Nicholson AA, Wedgwood KR, Mannion RA, Sedman PC, Royston CM, et al. Symptomatic malignant gastroesophageal anastomotic leak: management with covered metallic esophageal stents. AJR Am J Roentgenol 2001; 176: 161-5.
15. Doniec JM, Schniewind B, Kahlke V, Kremer B, Grimm H. Therapy of anastomotic leaks by means of covered self-expanding metallic stents after esophagogastrectomy. Endoscopy 2003; 35: 652-8.

16. Bartelsman JF, Bruno MJ, Jensema AJ, Haringsma J, Reeders JW, Tytgat GN. Palliation of patients with esophagogastric neoplasms by insertion of a covered expandable modified Gianturco-Z endoprosthesis: experiences in 153 patients. Gastrointest Endosc 2000; 51: 134-8.

17. Christie NA, Buenaventura PO, Fernando HC, Nguyen NT, Weigel TL, Ferson PF, et al. Results of expandable metal stents for malignant esophageal obstruction in 100 patients: short-term and longterm follow-up. Ann Thorac Surg 2001; 71: 1797-801.

18. Schubert D, Scheidbach H, Kuhn R, Wex C, Weiss G, Eder F, et al Endoscopic treatment of thoracic esophageal anastomotic leaks by using silicone-covered, self-expanding polyester stents. Gastrointest Endosc 2005; 61: 891-6.

19. Morán Ortiz de Solórzano M, Quintanilla Lázaro ME, Guerra Marina I, Collado Pacheco D, Castro Urda JL, Rábago Torre LR, et al. Oesophagopleural fistula in Barrett's oesophagus. Rev Esp Enferm Dig 2009; 101: 297-8.

20. Vakil N, Gross U, Bethge N. Human tissue responses to metal stents. Gastrointest Endosc Clin N Am 1999; 9: 359-65.

21. Langer FB, Wenzl E, Prager G, Salat A, Miholic J, Mang T, et al Management of postoperative esophageal leaks with the Polyflex self-expanding covered plastic stent. Ann Thorac Surg 2005; 79: 398-403.

22. Radecke K, Gerken G, Treichel U. Impact of a self-expanding, plastic esophageal stent on various esophageal stenoses, fistulas, and leakages: a single-center experience in 39 patients. Gastrointest Endosc 2005; 6: 812-8

23. Merrifield BF, Lautz D, Thompson CC. Endoscopic repair of gastric leaks after Roux-en-Y gastric bypass: a less invasive approach. Gastrointest Endosc 2006; 63: 710-4.

24. Freeman RK, Ascioti AJ, Wozniak TC. Postoperative esophageal leak management with the Polyflex esophageal stent. J Thorac Cardiovasc Surg 2007; 133: 333-8.

25. Eisendrath $\mathrm{P}$, Cremer M, Himpens $\mathrm{J}$, Cadière GB, Le Moine $\mathrm{O}$, Devière J. Endotherapy including temporary stenting of fistulas of the upper gastrointestinal tract after laparoscopic bariatric surgery. Endoscopy 2007; 39: 625-30.

26. Al-Haddad M, Craig CA, Odell J, Pajaro O, Wallace MB. The use of self-expandable plastic stents for non-malignant esophago-pleural fistulas. Dis Esophagus 2007; 20: 538-41.

27. Ott C, Ratiu N, Endlicher E, Rath HC, Gelbmann CM, Schölmerich $\mathrm{J}$, et al. Self-expanding Polyflex plastic stents in esophageal disease: various indications, complications, and outcomes. Surg Endosc 2007; 21: 889-96.

28. Turkyilmaz A, Eroglu A, Aydin Y, Tekinbas C, Muharrem Erol M, Karaoglanoglu N. The management of esophagogastric anastomotic leak after esophagectomy for esophageal carcinoma. Dis Esophagus 2009; 22: 119-26.

29. Pennathur A, Chang AC, McGrath KM, Steiner G, Alvelo-Rivera M, Awais $\mathrm{O}$, et al. Polyflex expandable stents in the treatment of esophageal disease: initial experience. Ann Thorac Surg 2008; 85: 1968-72.

30. Kauer WK, Stein HJ, Dittler HJ, Siewert JR. Stent implantation as a treatment option in patients with thoracic anastomotic leaks after esophagectomy. Surg Endosc 2008; 22: 50-3.

31. Tuebergen D, Rijcken E, Mennigen R, Hopkins AM, Senninger N, Bruewer M. Treatment of thoracic esophageal anastomotic leaks and esophageal perforations with endoluminal stents: efficacy and current limitations. J Gastrointest Surg 2008; 12: 1168-76.

32. Moxey PW, Khan AZ, Karanjia ND. A case of small-bowel perforation caused by a migrated duodenal stent. Endoscopy 2007; 39: E54.

33. Alanezi K, Urschel JD. Mortallity secondary to esophageal anastomotic leak. Ann Thorac Surg 2004; 10: 71-5. 